\title{
WELDED STRUCTURE OF KIEV TV-TOWER IS 40 YEARS OLD
}

\author{
L.M. LOBANOV, E.F. GARF, L.N. KOPYLOV and A.G. SINEOK \\ E.O. Paton Electric Welding Institute, NASU \\ 11 Bozhenko Str., 03680, Kiev, Ukraine. E-mail: office@paton.kiev.ua
}

\begin{abstract}
The basic moments connected with the fulfillment of assembly-welding works during building of Kiev TV-tower are described. The peculiar attention is paid to the application of automatic welding in increment of tower supports, as such solution was at the first time applied in practice of building of high-level constructions. 5 Figures.
\end{abstract}

$\boldsymbol{K} \boldsymbol{e} \boldsymbol{y} w \boldsymbol{w} \boldsymbol{r} \boldsymbol{s}:$ tower, welding, automatic welding, manual arc welding, pipes, assemblies

It has been 40 years since the day when the Kiev TV-tower was put into operation. During building of the tower the new design and technological solutions were used to demonstrate the successes and achievements of Kiev school of designing in the field of metal construction and capabilities of modern welding technologies. In spite of fierce resistance to the proposed project of the TV-tower from the side of the All-Union Association on Designing of Building Metal Structures, and also due to active support of Boris E. Paton, the President of the AS of Ukraine, and the UkrSSR Government, it was defended and realized.

Among the main advantages of the TV-tower project, which can serve as an example to follow even today, it cannot be but mentioned, first of all, the following:

- use of tubular sections for the tower elements manufactured of high-strength steel;

- application of connection of assemblies with direct attachment of elements to each other;

- manufacture of all-welded construction with a high rate of using automatic welding;

- application of erection of tower using the method of «increment» for the first time in the domestic practice of such constructions.

The essential component for successful realization of these progressive innovations was welding. We should note that volume of welding during erection of tower was very high, as the pipes were manufactured of a sheet and enlarged using circumferential butts. During erection all the joints were also produced using welding.

During construction of tower the automatic $\mathrm{CO}_{2}$ welding and manual electric arc welding using consumable electrode were used.
Manufacture of pipes. The pipes were manufactured of a sheet at the Zhdanov Heavy Machine-Building Plant. The technological process of manufacture of pipes envisaged the following succession of operations:

- edges preparation and chamfering for two longitudinal butt welds;

- cold stamping of billets (semi-pipes) of $4000 \mathrm{~mm}$ length;

- assembly and welding of pipes in a specially manufactured stand. The welding of outer and inner longitudinal butt welds was performed in accordance with the technology developed by the E.O. Paton Electric Welding Institute and the Laboratory of Central RSI of Shipbuilding Technology. Moreover, a specially developed smallsized tractor TS-42 for submerged arc welding of inner longitudinal welds was used. For the automatic submerged arc welding, wire $\mathrm{Sv}-08 \mathrm{~N} 2 \mathrm{M}$ in combination with flux $138 \mathrm{KF}-1$ was applied;

- quality control of welded joints;

- heat treatment of pipes for removal of inner stresses in the pipe formed in the process of formation of chutes and welding of longitudinal welds;

- calibration of pipe ends in the cold state allowing the performance of their alignment without special difficulties;

- final operation was chamfering for welding on the ends of pipes.

Automatic welding of circumferential butts of girths during erection of tower. The method of erection by «increment», accepted during development of the project of the tower, allowed performing all the basic welding-assembly works on welding the columns of the tower trunk from the stationary assembly sites, located at the height of $18 \mathrm{~m}$ from the ground surface and fastened on the guiding jig located inside the trunk of the tower (Figure 1). 


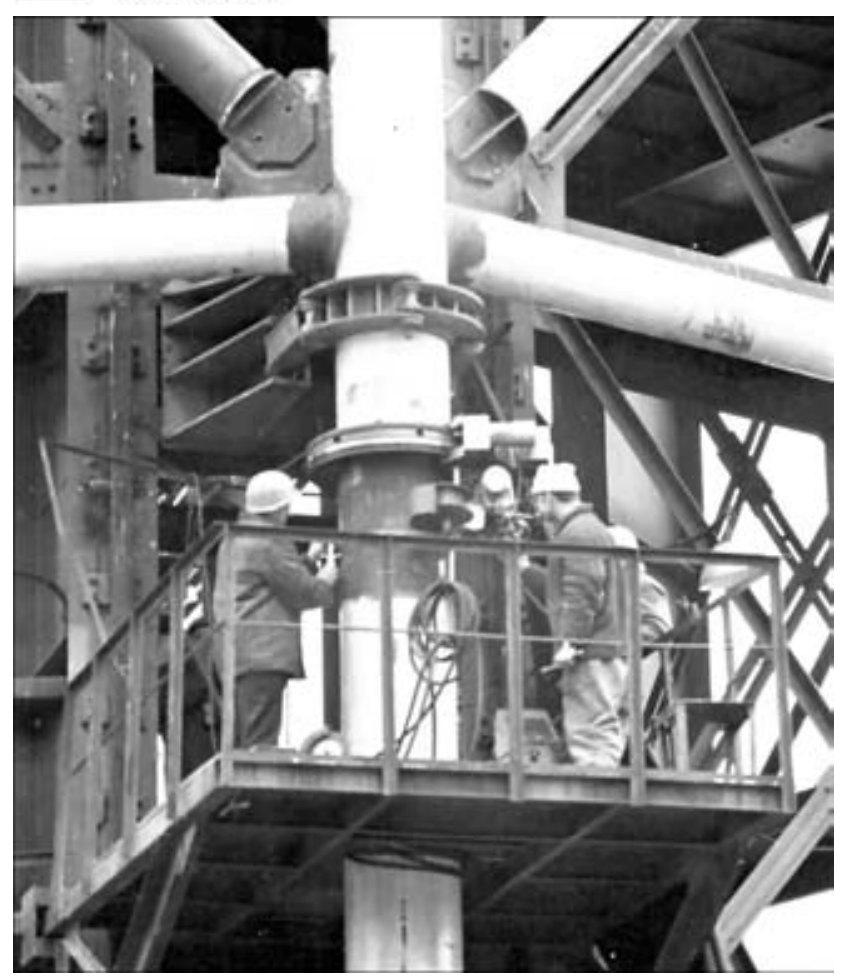

Figure 1. Removable erection platform for performance of automatic welding

This allowed applying the automatic welding during increment of the most critical elements of the tower ( 8 vertical columns of girth pipes of $550 \mathrm{~mm}$ diameter with the wall thickness of 18 and $22 \mathrm{~mm}$ ), and thus realizing all the advantages of automatic welding both from the point of view of quality guaranteeing, as well as from the position of labor capacity.

At the initial stage the works on development of the technique and technology of welding were fulfilled. The basic tasks solved at this stage: to provide the high quality of a weld and strength of welded joint not lower than the strength of

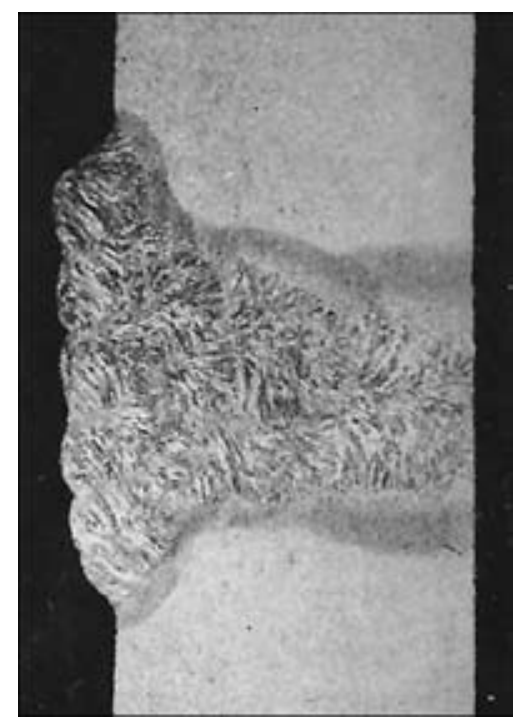

Figure 2. Macrosection of welded joint of a pipe produced using automatic $\mathrm{CO}_{2}$ welding base metan, and to obtain maximum efficiency of the welding process.

The experimental works on the development of technological process of automatic welding were performed by a group of associates (V.S. Krivosheya, the supervisor, L.N. Kopylov and V.M. Zil, leading engineers) under the leadership of B.Ya. Dubovetsky, the Laureate of the Lenin Prize, and Prof. B.F. Lebedev. PWI Research laboratories were also involved in the work. For the experimental research on development of technique and technology of welding of horizontal welds in a vertical plane the laboratory installation was mounted, on which the full-scale specimens of pipes were welded.

After welding of shells the quality of a weld was tested (ultrasonic flaw detection, gamma-ray examination), then the plates were cut out from the welded joint, the specimens for mechanical and metallographic investigations were manufactured. From the test results the correction of $\mathrm{pa}^{-}$ rameters of welded process was carried out, which was considered during fulfillment of the following experiments.

The girth pipes of the tower trunk were manufactured of steel IZ-138 with the increased strength characteristics. This steel melted at the Izhorsky Metallurgical Plant was at the first time applied in the practice of building of the objects of the tower type, therefore it was necessary to perform a large volume of investigations on its weldability. During conduction of experiments a number of difficulties were encountered. In particular, at the initial stage of investigations, during conduction of mechanical tests of welded joints, the positive results during bending tests of specimens (the requirement $-180^{\circ}$ ) were not achieved. The required results were achieved after application of the simple technological method of surfacing of four-five annealing beads on the lower and upper edges of a butt (Figure 2).

As a result of fulfilled experimental works the optimal V-shape edge preparation of butt joint of a pipe with minimum cross section area of a weld was found. Bevel of a low edge was equal to $11^{\circ}$, the upper one to $27^{\circ}$. The basic parameters of technological process were determined, the technique of automatic welding of horizontal circumferential welds in the vertical plane was developed providing the defect-free welded joints.

The developed technological process provided the equal strength of welded joint and base metal of pipes.

Basing on the data obtained during development of technique and technology of welding, the Technological Manual on welding of erection 
butts of girth pipes of tower trunk and the Technical Assignment on designing of the equipment for automatic welding of horizontal circumferential butts were worked out.

The development of the design of the equipment for welding of assembly butts of girth pipes of the tower trunk was performed under the supervision of Vladimir E. Paton. The main performers of design documentation were Yu.I. Saprykin and V.N. Kotov. During development of the design it was assumed that at erection of the tower trunks the loads would relieve simultaneously from two diametrically opposite vertical columns. Thus, the simultaneous welding of two butts could be performed. Therefore, to reduce the costs on reinstallation of welding equipment and to provide maximum labor efficiency of welding works, the decision was adopted to use simultaneously two sets of welding automatic machines during erection of the tower and to arrange the automatic machines on the transport carriage for convenient transportation of the equipment during welding of the following butts.

The team of designers of the PWI Experimental Design Bureau developed the design of specialized welding automatic machine A-1311 composed of the welding head with the guiding rail (Figure 3).

At the PWI Pilot Plant of Welding Equipment two sets of welding automatic machines A-1311 were manufactured. The equipment passed technological tests and was transferred to Construction and Election Organization of the UkrSSR Minmontazhspetsstroj.

The specialists of the E.O. Paton Electric Welding Institute conducted training of the welders team of the erection organization, which mastered successfully the technique of automatic welding and methods of work on welding automatic machines within a short period and were attested and obtained the permission to perform the works on automatic welding of site butts of girth pipes of the tower. For quality performance of automatic welding a number of organizationtechnical measures was carried out:

- at the building site the stand for preliminary control assembly of pipes being welded was equipped;

- in the zone of erection sites the tracks were mounted providing possibility of transportation of welding automatic machines from butt to butt;

- removable platforms were equipped mounted during welding of site butt and lowered during rise of the tower;

- quick-detachable tents protecting the erection site from wind during welding were manufactured;

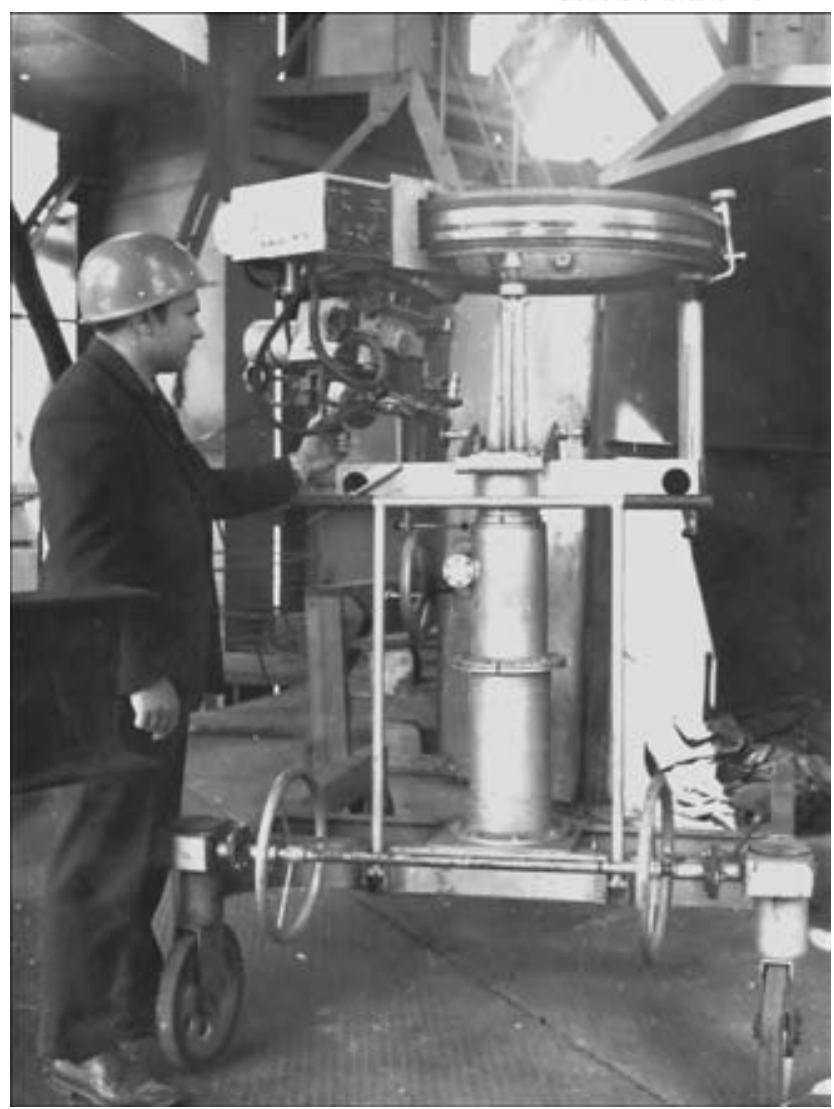

Figure 3. Welding machine A-1311 on the technological transport carriage

- erection sites for welding were provided with illumination.

The works on erection of the tower and also automatic welding of site butts of girth pipes were conducted in two shifts. The technological process of their assembly and welding was optimized.

On the stand for reference assembly of pipes two pipes were laid, which had to be aligned with each other, the most favorable arrangement of abutted ends was selected. To the end of the pipe, which will be the lower during assembly of the erection butt, a barrel-like metallic backing ring of $4 \mathrm{~mm}$ thickness was mounted. Then, on the side of the outer surface the ring was weldedon to the root area of the pipe by a solid weld around the whole perimeter of the ring. At the outer surface of pipes a mark was made by a paint allowing the repeating of given position of pipes during the assembly. After the unloading of two diametrically arranged jacks providing the lifting of tower, a lower pipe was installed on the jacks pushers, a pipe was brought to the lower end of the upper pipe using jacks and the technological gap in the root was set.

Before welding the automatic machine was moved to the place of welding, fastened on the butt being welded, the carriage was removed from 


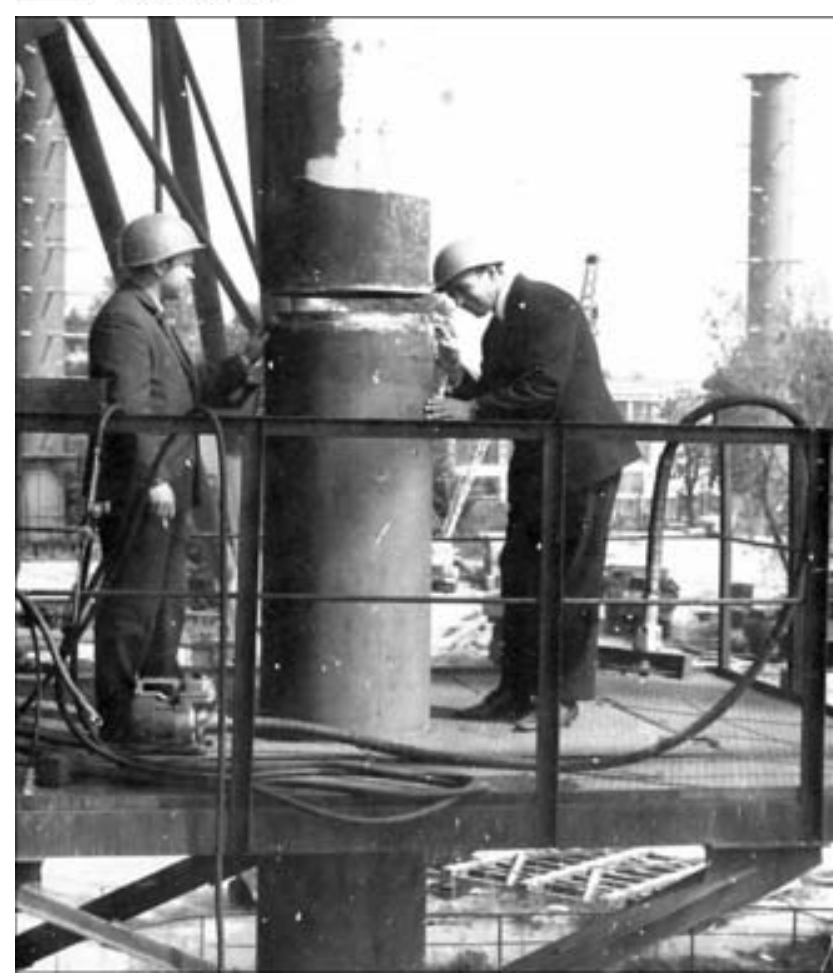

Figure 4. Quality control of assembly of circumferential butt

the erection site, and protective tent was installed.

The site butt was assembled at the technological gap of 3-4 $\mathrm{mm}$ in the root. The multipass welding of the site butt was performed with the preliminary heating of edges up to $180-200{ }^{\circ} \mathrm{C}$. For preheating the multi-flame gas oxygen-free torch was used, which was fastened on the welding machine ahead the welding nozzle. After heating of the initial area of a butt to the necessary temperature the welding process started.

For welding the electrode wire Sv-10GSMT of $1.2 \mathrm{~mm}$ diameter was applied. The welding of inner passes of a weld was performed at the current of 230-250 A and arc voltage of 23-24 V. The conditions of the finishing passes were the following: 50-180 A current, 19-21 V voltage. Depending on the thickness of the pipe wall (18 or $22 \mathrm{~mm}$ ) to fill the groove it was necessary to deposit 16-20 passes. The linear speed of welding of separate passes was $13-15 \mathrm{~m} / \mathrm{h}$.

During welding the periodic cleaning of the weld surface from a slag was performed using an abrasive tool. After completion of welding of a butt the cleaning of the surface of welded joint was performed using an abrasive tool, and the weld was given a barrel-like shape. Such a treatment improves the service characteristics of welded joint and enables the quality performance of ultrasonic testing of a weld.

Then $100 \%$ ultrasonic testing of welded joint was carried out. When it was necessary to specify the results, the gamma-ray examination was applied. Within the whole period of construction there was no a single case of repair of weld defects.

The total time of welding of one butt with the setting up of equipment, installation and disassembly of protective tent did not exceed $2.5 \mathrm{~h}$, where the duration of welding was not more than $1.5 \mathrm{~h}$.

Within the whole period of construction of Kiev TV-tower the specialists from the E.O. Paton Electric Welding Institute provided the author's supervision at all the stages of assembly-welding works of metal structures of the tower trunk (Figure 4) which contributed to the increase of quality of welded joints.

Manual electric arc welding. The considerable volume of works during construction of the tower was performed using manual consumable electrode arc welding. The control of all the operations connected with manual welding was performed by the PWI group of associates, headed by V.A. Kovtunenko.

The method of erection using «increment»allowed welding the elements of the grate (steel 20) with the tower supports not at a great height, within the range of two tiers. As the joining of elements of grate with the supports was performed by direct attachment along the spatial curve, a great attention was paid to cutting-on of pipe ends of grate elements (Dnepropetrovsk I.V. Babushkin Steelwork Plant). For this purpose the Plant together with the All-Union RSI «Avtomat» and Odessa Plant «Avtogenmash» manufactured the machine providing cutting-on of ends of the required quality. Only in single cases during erection the fitting-up was required to provide the required gaps.

The assembled joints of elements were admitted to welding after their acceptance by a representative from the E.O. Paton Electric Welding Institute and a welding inspector of C\&EO with registration in the log book of assembly works. The marking was made on the joint allowing welding to be performed.

The welding was performed using low-hydrogen electrodes of $48 \mathrm{~N}-1$ grade providing the mechanical properties of welded joint on the level of steel of S-60 class. The welding was performed at the temperature of not lower than $-15{ }^{\circ} \mathrm{C}$. Independently of the temperature of the environment, in welding of assembly joints the preheating to $50-60{ }^{\circ} \mathrm{C}$ was applied to remove condensate. The welding was performed using in-line multilayer welds (Figure 5). 
Sticking between the beads was regulated within the range of $1.0-1.2 \mathrm{~mm}$ with a smooth transition from weld metal to base metal.

The joints on the areas of complete penetration were tested using ultrasonic method. In some spots, which required profound decoding of testing results, the gammagraphy was applied. The development of procedures and control were performed by the PWI associates.

Using manual electric arc welding a considerable amount of butt joints of pipes in the support part, in the support of grate part of the antenna «Altaj» and stem of the antenna were performed.

The butt joints were performed on the backing ring using the same welding consumables. At the E.O. Paton Electric Welding Institute the technology and technique of welding, optimal conditions providing the stable quality of welded joints were tested. All the welders passed qualification selection with the obligatory welding of reference specimens. In welding of steel of grade $14 \mathrm{KhGN} 2 \mathrm{MD}$ (IZ-138) the preheating up to 160$200{ }^{\circ} \mathrm{C}$ was necessary. In the rest the requirements to welded joints were similar to those accepted for assembly joints.

The other joints (frame of the building, links, platforms) were also made using manual electric arc welding.

In conclusion one cannot but note that even after 40 years the Kiev TV-tower is the example of perfection of engineer idea and also a high level of design and technologies used during construction.

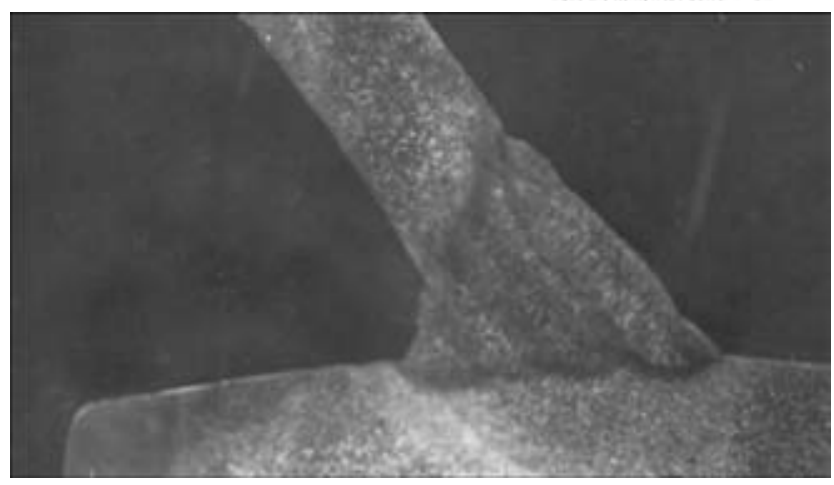

Figure 5. Macrosection of joint produced using manual electric arc welding

In building of the tower a great number of engineers-designers, scientists, erectors, engineers and workers of building specialties took part. Each of them made his great contribution into the creation of a unique construction, decorating Kiev even today. On the occasion of anniversary date from the day of creation of the tower the contribution of O.I. Shumitsky and V.I. Novikov should be especially marked, who made great efforts to realize the project in a form in which it was realized, decided to implement new and extraordinary for that time engineering solutions. And one should note also the support of new ideas on the side of B.E. Paton, without which the realization of the project under those conditions would be unreal. 